\title{
Pola Asuh Demokrasi dan Nilai-Nilai Agama Dalam Keluarga di Lingkungan Beragam Agama Desa Suka Julu Dusun III Jumpa
}

\section{Parenting Democracy and Religious Values In Families in Various Religious Environments at Suka Julu Village, Dusun III Jumpa}

\author{
Laili Alfita, Risydah Fadilah, \& Muhammad Irsan Barus \\ Fakultas Psikologi, Universitas Medan Area, Indonesia \\ Diterima: Juli 2019 ; Disetujui: Agustus 2019 ; Dipublish: September 2019
}

\begin{abstract}
Abstrak
Pengabdian ini bertujuan Membangun pola Asuh Demokratis dan Membangun nilai-nilai Agama. Lokasi pengabdian di Desa Suka Julu Dusun III Jumpa. Metode Pelaksanaan dalam pengabdian ini melalui ceramah, permainan game, perenungan dan konsultasi. Hasil kegiatan Setelah dilakukan kegiatan tersebut, maka diperoleh hasil bahwa hampir 60\% masayarakat masih menjalankan pola Asuh permisif dan akan mencoba untuk merubahnya dengan pola Asuh Demokratis. Desa Suka Julu Dusun III Jumpa merupakan salah satu desa yang terletak di tanah karo dengan masyarakat yang beragam agama walaupun lebih didominasi oleh suku Karo di daerah sekitar kota Berastagi. Dalam adat istiadat, bagi anak perempuan tidak diperbolehkan untuk berbicara dengan bapaknya. Selain itu, masih kurangnya penanaman nilai-nilai agama. Masih ada yang belum memiliki keyakinan agama yang kuat, sehingga pada hari Natal, masih ada yang umat Islam mengikuti kegiatan agama Kristen dan demikian sebaliknya. Hal ini tentu membingungkan bagi anak. Sehingga akan melahirkan anak-anak yang kurang dalam kepercayaan dirinya. Berdasarkan uraian tersebut, maka dapat disimpulkan bahwa masih terdapat 40\% masyarakat yang menggunakan pola Asuh Demokratis. Pelaksanaan nilai-nilai agama dilingkungan keluarga, dari hasil penelitian yang dilakukan hanya mencapai $20 \%$. Hasil ceramah pada orang tua, dapat dilihat peningkatan pemahaman pola asuh telah mencapai $55 \%$. Sedangkan penanaman nilainilai agama masih tetap $20 \%$.
\end{abstract}

Keyword : Pola Asuh Demokrasi, Nilai Agama, Keluarga.

\section{Abstract}

This service aims at this service is Building a pattern of Democratic Care and Building the values of Religion. It should be understood that the family is two or more individuals who live in one household because of the relationship of blood, marriage and interacting with one another, having their respective roles by creating and maintaining a culture. The environment that is first encountered by children is the family environment. In the family of course there are religious values born from generation to generation and carried by the family. Whereas religious experience is an element of feeling in religious consciousness, namely the feeling that leads to beliefs generated by actions or amaliyah. Suka Julu Village Hamlet III Jumpa is one of the villages located in Karo land with diverse religious communities although it is dominated by Karo tribes in the area around Berastagi city. In customs, girls are not allowed to talk with their father. In addition, there is still a lack of planting of religious values. There are still those who do not have strong religious beliefs, so that on Christmas day, there are still Muslims who follow Christian activities and vice versa. This is certainly confusing for children. So that it will give birth to children who lack confidence. Personality dynamics actively influence human activities. Spiritual energy functions to regulate spiritual activities such as thinking, remembering, observing and so on. The instinct function regulates primary needs: eating, drinking and sexual. The ego has the function of adjusting impulse adjustment with objective reality. While Super Ego functions as a giver of inner rewards (satisfied, happy, successful) and punishment (guilt, sin, regret). The reward is played by the ideal ego, and inner punishment is carried out by the conscience. This activity was carried out to foster democratic upbringing and religious values in families in various religious environments in a tribe.

Keywords: Parenting Democracy, Religious Values, Family.

How to cite : Alfita L. Fadilah, R \& Barus M,I. (2019). Pelatihan Pembuatan Saus Tomat. Pelita Masyarakat : Jurnal Pengabdian Masyarakat 1(1) :30-38 


\section{PENDAHULUAN}

Mengkaji mengenai keluarga, tentu tidak dapat terlepas dari ayah, ibu dan anak. Ayah dan ibu memiliki andil yang besar dalam kesuksesan suatu keluarga. Keluarga merupakan dua atau lebih individu yang hidup dalam satu rumah tangga karena adanya hubungan darah, perkawinan serta saling berinteraksi satu dengan yang lain, mempunyai peran masing-masing dengan menciptakan serta mempertahankan suatu budaya. Budaya juga tidak dapat terlepas dari keluarga. Hal ini sebagaimana gambaran mengenai aktivitas dalam keluarga tentu terkait dengan budaya. Budaya merupakan kebiasaan yang dilakukan atas keinginan bersama yang dihasilkan dari situasi-situasi yang telah dikondisikan.

Keluarga menjalankan situasi-situasi yang telah dikondisikan tersebut, tanpa bisa menyatakan suka atau tidak suka. Hal ini yang sering berdampak pada anak. Anak merupakan hasil dari hubungan antara pria dan wanita, yang diikat dalam suatu perkawinan atau keinginan bersama. Anak yang lahir dipermukaan bumi tidak pernah berharap untuk dilahirkan, tetapi mereka butuh diperhatikan, disayangi, dicintai, dan dihargai.

Hal tersebut akan terbentuk dari keberadaan lingkungan. Lingkungan yang pertama sekali dijumpai anak adalah ligkungan keluarga. Lingkungan keluarga memiliki nuansa yang sangat mempengaruhi dalam kehidupan perkembangan anak. Anak yang lingkungan keluarga yang keras, tentu akan melahirkan anak-anak yang keras pula. Anak yang dilahirkan dengan lingkungan yang tidak peduli, akan melahirkan anak-anak yang tidak memiliki rasa kepedulian dan egois. Sedangkan anak yang dilahirkan dengan penuh perhatian dan toleransi, maka akan melahirkan anak-anak yang mampu memahami orang lain, dan memiliki rasa menyayangi dengan keluarganya.

Terciptanya hal-hal tersebut diatas dikarenakan ada yang disebut dengan Imitasi. Imitasi merupakan peniruan. Peniruan ini yang menciptakan anak-anak sesuai dengan karakter yang telah ditanamkan oleh orang tuanya. Disisi lain, anak juga dipengaruhi oeh faktor external, sehingga anak akan terpengaruh oleh aktivitas lingkungan luar keluarga. Dalam keluarga tentu ada nilai-nilai agama. Biasanya nilai-nilai agama terlahir dari turun temurun dan dibawa oleh keluarga. Nilai-nilai agama sering 
menjadi tatanan kehidupan yang menciptakan suatu nuansa dalam keluarga yang berbeda dari keluarga-keluarga yang lainnya. Nilai-nilai agama juga mengambil peran penting dalam kehidupan berkeluarga, sebagaimana ungkapan dalam Surah Kahfi : 46 'Harta \& Anak-Anak Adalah Perhiasan Kehidupan Dunia” .Selain itu, dalam surah At-Tahriim ayat 6 yang menyatakan;

"Hai orang-orang yang beriman, peliharalah dirimu dan keluargamu dari api neraka yang bahan bakarnya adalah manusia dan batu, penjaganya malaikat-malaikat yang kasar, keras, dan tidak mendurhakai Allah terhadap apa yang diperintahkan-Nya kepada mereka dan selalu mengerjakan apa yang diperintahkan."

Memahami nilai-nilai agama pada seseorang akan tergambar dari prilaku yang dimanifestasikannya didalam kehidupan sehari-hari. Kesadaran agama adalah bagian agama yang hadir (terasa) dalam pikiran yang merupakan aspek mental. Sedangkan pengalaman agama adalah unsur perasaan dalam kesadaran beragama, yakni perasaan yang membawa kepada keyakinan yang dihasilkan oleh tindakan atau amaliyah. (dalam Daradjat 1970)

Ungkapan diatas tentu memberi gambaran bahwa keluarga adalah hal utama yang perlu dijaga dan diarahkan kepada jalan yang benar. Akan tetapi, sebagai orang tua, sering melupakan bahwa orang tua memiliki tanggung jawab untuk memberikan contoh yang baik. Orang tua sering lalai memperhatikan anak-anaknya. Orang tua sering hanya memberikan fasilitas tanpa mempertanyakan, apa yang dibutuhkan anak-anak tersebut.

Sikap tersebut tergambar dari masyarakat yang ada di Desa Suka Julu Dusun III Jumpa. Dalam adat istiadat, bagi anak perempuan tidak diperbolehkan untuk berbicara dengan bapaknya. Selain itu, masih kurangnya penanaman nilai-nilai agama. Masih ada yang belum memiliki keyakinan agama yang kuat, sehingga pada hari Natal, masih ada yang umat Islam mengikuti kegiatan agama Kristen dan demikian sebaliknya. Hal ini tentu membingungkan bagi anak. Sehingga akan melahirkan anak-anak yang kurang dalam kepercayaan dirinya.

Berdasarkan uraian diatas, maka Batasan Masalah pengabdian Masyarakat adalah : terkait mengenai pemberian Pola Asuh Demokratif dan nilai-nilai Agama dalam keluarga yang dilaksanakan di desa Suka Julu Dusun III Jumpa. Setelah dilakukan 
peninjauan, wawancara, observasi dan diberikan screening, maka diperoleh gambaran bahwa pola asuh yang dimiliki masyarakat di Desa Huta Julu Tanah Karo, hampir 60\%, melaksanakan pola Asuh permisif. Terkait dengan penanaman nilai-nilai agama, tergambar bahwa di Desa Huta Julu, masih belum melaksanakan kegiatan agama sesui dengan ketentuan agama yang dianut. Adapun Tujuan Pengabdian Masyarakat ;Membangun pola Asuh Demokratis dan Membangun nilai-nilai Agama. Selain itu, Manfaat Pengabdian Masyarakat ; - Melalui pengabdian ini diharapkan, akan menambah pengetahuan dalam membangun pola asuh dan nila-nilai agama dalam keluarga. Hal ini sangat bermanfaat bagi keluarga dan juga masyarakat. Juga bagi lembaga sosial dan juga lembaga Agama.

\section{ANALISIS SITUASIONAL}

[wu1] Menurut pendekatan psikologi analisa, dalam diri terdapat dinamika kepribadian, yakni: 1) energi rohaniah; 2) naluri; 3) ego; dan 4 ) super ego. Menurut Sigmund Freud, dinamika itu secara aktif ikut mempengaruhi aktivitas manusia. Energi rohani fungsinya mengatur aktivitas rohaniah seperti berpikir, mengingat, mengamati dan sebagainya. Fungsi naluri mengatur kebutuhan primer: makan, minum dan seksual. Ego fungsinya mengatur penyesuaian dorongan dengan kenyataan objektif. Sementara Super Ego berfungsi sebagai pemberi ganjaran batin (puas, senang, sukses) dan hukuman (rasa bersalah, berdosa, menyesal). Penghargaan diperankan oleh ego ideal, dan hukuman batin dilakukan oleh hati nurani.(dalam Jalaluddin 2015)

Dampak-dampak psikologis ini yang sering tidak terpantau oleh orang tua. Fenomena yang juga tergambar dari Desa Huta Julu Tanah Karo, terkait dengan faktor Ekonomi yang juga mempengaruhi pola asauh seseorang, dan juga nilai-nilai agama. Hal ini tergambar dari sikap orang tua yang kurang peduli dengan prilaku anak dan mengorbankan nilai-nilai agama yang telah ditanamkan dalam keluarga.

Papalia dan Feldman (2014) mengungkapkan bahwa kerugian yang diakibatkan oleh kemiskinan mungkin secara tidak langsung, melalui dampak kondisi emosional orang tua dan praktik pengasuhan serta pada lingkungan tempat tinggal yang mereka buat. Selain itu Papalia dan Feldman (2014), juga mengungkapkan bahwa kemiskinan 
khususnya jika bertahan lama, dapat membahayaka fisik, kognitif dan kesejahteraan psikososial anak dan keluarga.

Kondisi-kondisi ini menggambarkan lemahnya iman, kurangnya penanaman nilainilai agama. Selain itu dalam pola asuh, juga memberi peluang bagi anak untuk menjadi orang yang kurang peduli terhadap lingkungan, dikarenakan sikap lingkungan keluarga mendukung hal tersebut. Oleh karena itu, dalam membangun rumah tangga sangat diperlukan pola asuh yang demokratis dan adanya nilai-nilai agama dalam keluarga. Pola Asuh demokratis, merupakan pola asuh yang memprioritaskan kepentingan anak, akan tetapi tidak ragu dalam mengendalikan mereka. Orang tua dengan perilaku ini bersikap rasional, selalu mendasari tindakannya pada rasio atau pemikiran-pemikiran. Orang tua tipe ini juga bersikap realistis terhadap kemampuan anak, tidak berharap yang berlebihan yang melampaui kemampuan anak. orang tua tipe ini juga memberikan kebebasan kepada anak untuk memilih dan melakukan suatu tindakan dan pendekatannya kepada anak bersifat hangat.

Hal ini tergambar dari ungkapan Hulock (1980), bahwa kecendrungan untuk menyenangi disiplin yang berdasarkan prinsip-prinsip demokratis sekarang meningkat. Prinsip demikian menekankan hak anak untuk mengetahui mengapa peraturanperaturan dibuat dan memperoleh kesempatan mengemukakan pendapatnya sendiri bila ia menganggap bahwa peraturan itu tidak adil.

Dsisi lain dalam membangun nilai-nilai agama tentu tidak terlepas dari pola asuh yang telah dibudayakan dalam keluarga, sehingga hal tersebut akan sejalan dalam membangun pola asuh dan nilai-nilai agama dalam keluarga. Aisyah Raddhiyalahu Anha berkata "Nabi Shallalahu Alaihi wa Salam bersabda; “Wahai Aisyah, sesungguhnya Allah itu lembut dan menyukai kelembutan, Dia memberikan sesuatu pada kelembutan yang tidak diberikan kepada sikap keras dan tidak pula diberikan kepada yang lainnya." (Bukhari no. 6927 dan Muslim no. 2593, dalam Muhammad 2011)

Ungkapan tersebut, tentu menggambarkan, bahwa dalam menghadapi anak-anak yang dilahirkan, dibutuhkan orang tua yang dapat bersikap lemah lembut. Kekerasan tidak selamanya melahirkan anak yang tegas, tetapi dapat melahirkan anak-anak yang pendendam, pemarah dan kasar, bahkan dapat juga melahirkan anak yang penakut, sehingga tidak mampu mengungkapkan kebenaran. 


\section{METODE PELAKSANAAN}

Pengabdian Masyarakat ini dilaksanakan selama 2 (dua) hari pada tanggal 27 -28 Oktober 2018,pada masyarakat yakni remaja dan orang tua di desa Suka Julu Dusun III Jumpa. Durasi Pelaksanaan dilakukan mulai dari waktu malam (20.00 wib sampai dengan $23.00 \mathrm{wib}$ ) pada hari pertama dan hari kedua dari pagi sampai siang. ( $08.00 \mathrm{wib}$ sd 12.30 wib ). Materi pengabdian ini Asuh Demokratis dan Agama.

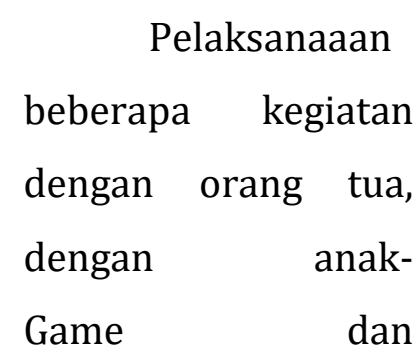

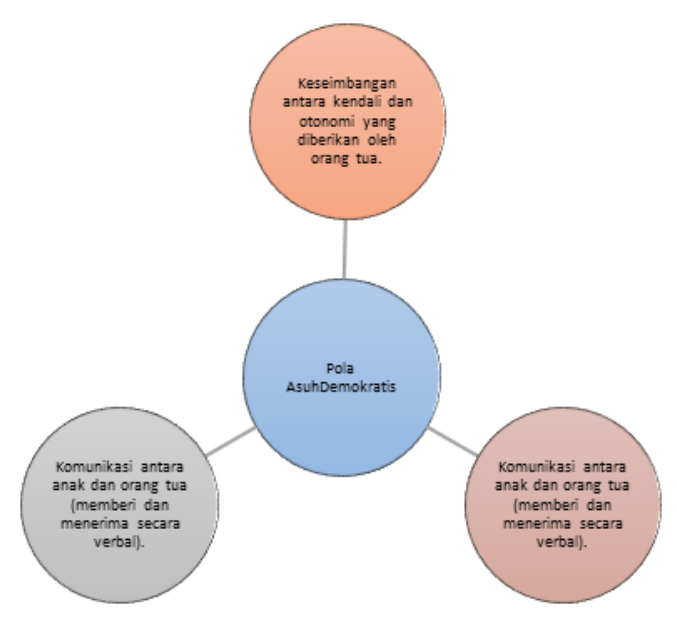
dalam pelaksanaan terkait Membangun pola Membangun nilai-nilai dilakukan dengan antara lain : Ceramah konsultasi, Ceramah anaknya, Permainan Perenungan.

Gambar 1-1 Pola Asuh Demokratis,melalui Aspek-aspek Pola Asuh Demokratis Menurut Santrock (2003):

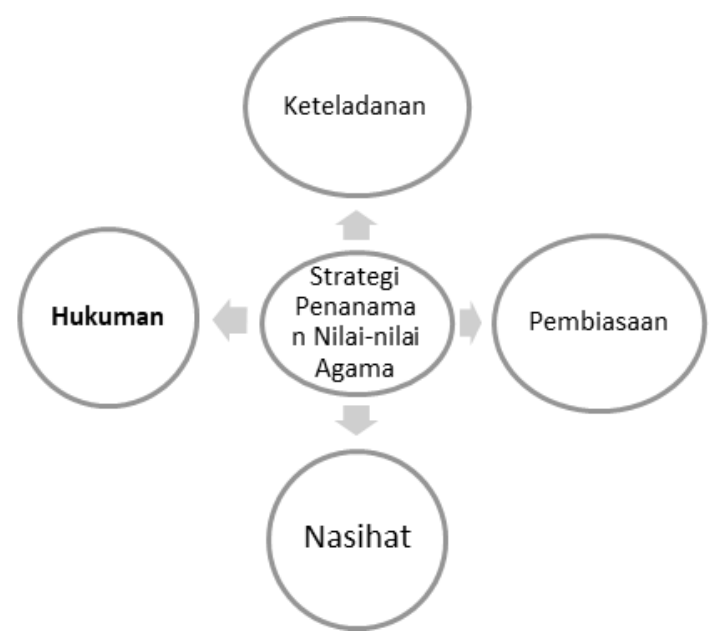

Gambar 1-2. strategi yang dapat digunakan dalam menanamkan nilai-nilai keagamaan (dalam Djamar dan Zain, 2006) antara lain 


\section{HASIL DAN PEMBAHASAN}

Faktor-faktor yang mempengaruhi pola asuh demokratis antar lain :Pengaruh keluarga asal, Hubungan orang tua dengan anak, Sikap penolakan orang tua, Figur orang tua ,Ketergantungan yang berlebihan terhadap orang lain.

Pola asuh sangat penting dalam mendidik perilaku anak, membentuk peribadian, dan perilaku anak, poal asuh adalah gaya pengasuhan yang digunakan orang tua dalam mendidik anaknya. Kohn (dalam Casmini, 2007) menyatakan bahwa pengasuhan merupakan cara orang tua berinteraksi dengan anak yang meliputi, pemberian aturan, hadiah, hukuman dan pemberian perhatian, serta tanggapan terhadap perilaku anak. Banyak ahli mengatakan pengasuhan anak adalah bagian penting dan mendasar, menyiapkan anak untuk menjadi masyarakat yang baik .

Dalam bidang keilmuan psikologi pendidikan, metode pembisaan dikenal dengan istilah operan conditioning, mengajarkan peserta didik untuk membiasakan perilaku terpuji, disiplin, giat belajar, bekerja keras, ikhlas, jujur, dan bertanggung jawab atas setiap tugas yang telah diberikan. Pembiasaan sengaja melakukan sesuatu secara berulang-ulang agar sesuatu itu dapat menjadi kebiasaan. Pembiasaan sebenarnya berintikan pengalaman, yang dibiasakan adalah sesuatu yang diamal-kan. Pembiasaan menentukan manusia sebagai sesuatu yang diistemawakan, yang dapat menghemat kekuatan, karena akan menjadi kebiasaan yang melekat dan spontan agar kekuatan itu dapat dipergunakan untuk berbagai kegiatan dalam setiap pekerjaan dan aktivitas lainnya.

Dalam kehidupan sehari-hari, pembiasaan merupakan hal yang sangat penting, karena banyak dijumpai orang berbuat dan berperilaku hanya karena kebiasaan sematamata. Pembiasaan dapat mendorong mempercepat perilaku, dan tanpa pembiasaan hidup seseorang akan berjalan lamban, sebab sebelum melakukan sesuatu harus memikirkan terlebih dahulu apa yang akan dilakukannya. Metode pembiasaan penanaman nilai-nilai keagamaan kepada peserta perlu diterapkan oleh guru dalam proses pembentukan karakter, untuk membiasakan peserta didik dengan sifat-sifat terpuji dan baik, sehingga aktivitas yang dilakukan oleh peserta didik terekam secara positif. 
Setelah dilakukan kegiatan tersebut, maka diperoleh hasil bahwa hampir $60 \%$ masayarakat masih menjalankan pola Asuh permisif dan akan mencoba untuk merubahnya dengan pola Asuh Demokratis. Orang tua akan berusaha merubah kegiatan agamanya dirumah dan kegiatan nilai-nilai agama dalam keluarga,dengan cara saling merubah cara kegiatan yang ada dirumah.

\section{SIMPULAN}

Masih terdapat 40\% masyarakat yang menggunakan pola Asuh Demokratis. Pelaksanaan nilai-nilai agama dilingkungan keluarga, dari hasil penelitian yang dilakukan hanya mencapai $20 \%$.

Hasil ceramah pada orang tua, dapat dilihat peningkatan pemahaman pola asuh telah mencapai 55 \%. Sedangkan penanaman nilai-nilai agama masih tetap 20\%.

\section{UCAPAN TERIMAKASIH}

Terimakasih kepada masyarakat Desa Suka Julu Dusun III Jumpa. Terimakasih Kepada Bapak Pengurus Mesjid yang telah memberi penginapan selama pengabdian ini berlangsung.

\section{DAFTAR PUSTAKA}

Ali, Muhammad. (2008). Psikologi Remaja. PT Bumi Aksara. Jakarta.

Alberti, R. dan Emmons, M., (2002). Your Perfect Right. Penterjemah Buditjahya, PT. Elex Media Komputindo, Jakarta.

Bower, S. A., \& Bower, G. H. (1992). Asserting your self: A practical guide for positive change. (updated). California: Addison Wesley.

Casmini, (2007). Emotional Parenting: Dasar-Dasar Pengasuhan Kecerdasan Emosi Anak. Yogyakarta: Macmillan.

Drew, Edwards, (2006). Ketika Anak Sulit Diatur. Penerjemah: Ida Farida. Bandung: PT. Mizan Pustaka.

Daradjat, Zakiah , (1970) Ilmu Djiwa Agama Jakarta: Bulan Bintang.

Gunarsa, Y. S. D (2003). Psikologi Perkembangan Anak Dan Remaja. Penerbit Erlangga.

Hurlock, B, Elizabeth, (1980), Development Psychology , McGraw-Hill,Inc.

Hurlock, E. B. (2009). Psikologi Perkembangan: Suatu Perkembangan Sepanjang Rentang Kehidupan.Jakarta: Erlangga.

Irwanto. (2002). Psikologi Umum. Jakarta:PT Prenhallindo. 
Laili Alfita, Risydah Fadilah, \& Muhammad Irsan Barus, Parenting Democrazcy and Relegious Values in

Jalaluddin, (2015) Tingkat Usia dan Perkembangan Spiritualitas serta Faktor yang Melatarbelakanginya di Majelis Tamasya Rohani Riyadhul Jannah Palembang, Jurnal Intizar, Vol. 21, No. 2.

King, A. Laura (2010). Psikologi Umum. Jakarta: Salemba Humanika.

Lestari, Sri. (2012). Psikologi Keluarga: Penanaman Nilai dan Penanganan Konflik dalam Keluarga. Jakarta: Prenada Media Group

Muhammad, (2011), Ensiklopedi Islam Al-Kamil, Darus Sunnah Cetakan 11 Jakarta.

Marini, L., \& Andriani, E (2005). Perbedaan Asertivitas Remaja Ditinjau Dari Pola Asuh Orang Tua. Psikologia. 1(2), 46-53.

Miasari, Astri (2012). Hubungan Antara Komunikasi Positif Dalam Keluarga Dengan Asertivitas Pada Siswa SMP Negeri 2 Depok Yogyakarta. Jurnal Empathy. 1(1), 32-36

Nazir, Moh (2005). Metode Penelitian. Jakarta: Ghalia Indonesia.

Papalia, E. D. Dan Feldman, R. T. (2014). Menyelami Perkembangan Manusia ; Experience Human Development. Jakarta: Salemba Humanika.

Rakos, R.F. (1991). Assertive behavior: theory, research \& training. New York: Routledge, Chapman \& Hall Inc.

Santrock, J. W. (2003). Adolescent Perkembangan Remaja. Jakarta : PT. Erlangga.

Santrock, J. W. (2007). Life Span Development : Perkembangan Masa Hidup (Jilid 2). Jakarta : PT. Erlangga.

Sarwono. S. W. (2011). Psikologi Remaja. Jakarta: Rajawali Pers.

Sugiyono. (2007). Metode Penelitian Pendidikan. Bandung.

Supangat, Andi (2010). Statistika :Dalam Kajian Deskriptif, Inferensi dan Non Parametrik (3rded). Jakarta : Kencana

Thoha Chabib M (1996) , Kapita Selekta Pendidikan Islam Yogyakarta: Pustaka Pelajar, hlm. 60

Wiwit Wahyuning, Jash, dan Metta Rachmadian,(2003). Mengkomunikasikan Moral kepada Anak. Jakarta: PT Elex Media Komputindo Kelompok Gramedia.

Zulkifli, L. (2009). Psikologi Perkembangan.PT. Remaja Rosdakarya. 